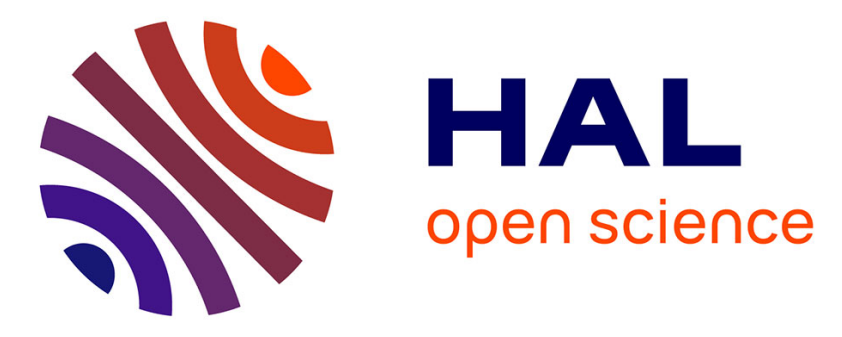

\title{
Patency of the supraclinoid internal carotid artery branches after flow diversion treatment. A meta-analysis
} Federico Cagnazzo, Pierre-Henri Lefevre, Daniel Mantilla, Aymeric Rouchaud, Riccardo Morganti, Paolo Perrini, Davide Di Carlo, Cyril Dargazanli, Gregory Gascou, Carlos Riquelme, et al.

\section{- To cite this version:}

Federico Cagnazzo, Pierre-Henri Lefevre, Daniel Mantilla, Aymeric Rouchaud, Riccardo Morganti, et al.. Patency of the supraclinoid internal carotid artery branches after flow diversion treatment. A meta-analysis. American Journal of Neuroradiology, 2019, 46 (1), pp.9-14. 10.1016/j.neurad.2018.07.006 . hal-02395585

\section{HAL Id: hal-02395585 \\ https://hal.science/hal-02395585}

Submitted on 21 Oct 2021

HAL is a multi-disciplinary open access archive for the deposit and dissemination of scientific research documents, whether they are published or not. The documents may come from teaching and research institutions in France or abroad, or from public or private research centers.
L'archive ouverte pluridisciplinaire HAL, est destinée au dépôt et à la diffusion de documents scientifiques de niveau recherche, publiés ou non, émanant des établissements d'enseignement et de recherche français ou étrangers, des laboratoires publics ou privés.

\section{(ㄷ)(1) $\$$}

Distributed under a Creative Commons Attribution - NonCommerciall 4.0 International 


\section{Patency of the Supraclinoid Internal Carotid Artery Branches after Flow- \\ Diversion Treatment}

\section{A Meta-Analysis}

Federico Cagnazzo MD ${ }^{1}$, Pierre-Henri Lefevre MD ${ }^{1}$, Daniel Mantilla MD ${ }^{1}$, Aymeric Rouchaud $\mathrm{MD}^{3}$, Riccardo Morganti $\mathrm{MD}^{2}$, Paolo Perrini $\mathrm{MD}^{4}$, Davide Di Carlo MD${ }^{4}$, Cyril Dargazanli $\mathrm{MD}^{1}$, Gregory Gascou $\mathrm{MD}^{1}$, Carlos Riquelme $\mathrm{MD}^{1}$, Alain Bonafe $\mathrm{MD}^{1}$, Vincent Costalat $\mathrm{MD}^{1}$

${ }^{1}$ Neuroradiology department, University Hospital Güi-de-Chauliac, CHU de Montpellier, Montpellier, France.

${ }^{2}$ Department of Clinical and Experimental Medicine, Section of Statistics, University of Pisa, Pisa, Italy

${ }^{3}$ Interventional Neuroradiology NEURI Center, Hôpital Bicêtre, Le Kremlin Bicêtre, France

${ }^{4}$ Department of Neurosurgery, University of Pisa, Pisa, Italy

Corresponding Author: Dr. Federico Cagnazzo, Neuroradiology department, CHU Gui De Chauliac, 80 Avenue Augustin Fliche, 34000 Montpellier, France Tel: +33 695053659 E-mail: f.cagnazzo86@gmail.com 
Patency of the Supraclinoid Internal Carotid Artery Branches after Flow-

Diversion Treatment

A Meta-Analysis 


\section{Abstract}

Background and purpose: Placement of flow diverters across the ostia of major internal carotid artery (ICA) branches carries a risk of arterial occlusion. We determined the rate of occlusion of the supraclinoid ICA branches and the related symptoms, following coverage with flow diverters.

Materials and methods: A systematic search was performed in PubMed, MEDLINE, and EMBASE. We selected studies reporting treatments with flow diverters in which the device was placed across the ostium of the OphtA, PcomA, or AchorA. Random-effects meta-analysis was used to pool the following outcomes: rate of arterial occlusion, diminished flow, incidence of related symptoms, factors associated with arterial occlusion.

Result: Twenty-one studies evaluating 1152 supraclinoid ICA branches were included in the metaanalysis. The incidence of OphtA occlusion and associated symptoms was $5.9 \%$ (95 CI\%=3.1$8.6 \%)$ (incidence $=6 \%$ per patient-year), and $0.8 \%(95 \% \mathrm{CI}=0.1-1.4 \%)$ (incidence $=0.8 \%$ per patient-year), respectively. Although asymptomatic in all cases, PcomA showed a higher occlusion rate $(20.7 \%, 95 \% \mathrm{CI}=8.9-32.4 \%)$ (incidence $=19.5 \%$ per patient-year). AchorA was occluded in $1 \%(95 \% \mathrm{CI}=0.3-2.4 \%)$ of cases, with approximately $1 \%(95 \% \mathrm{CI}=0.4-2.3 \%)$ of transient neurological symptoms (incidence $=0.96 \%$ per patient-year). There was a trend toward higher odds of arterial patency among arteries arising from the aneurysm $(\mathrm{OR}=2.94, \mathrm{p}=0.06)$. Demographic factors and multiple stents were not associated with higher risk of arterial impairment. Adequate collateral circulation was reported in $94.5 \%$ of patients with arterial occlusion.

Conclusions: During aneurysm treatment, the ostium of the supraclinoid ICA branches can be covered with flow-diverter devices with low rates of neurological symptoms related to arterial occlusion.

Key Words: flow diversion; intracranial aneurysms; pipeline; endovascular treatment; patency; side branches occlusion 


\section{Introduction}

Flow-diverter stents are increasingly being used in the treatment of cerebral aneurysms, giving a high rate of aneurysm shrinkage and occlusion. A large number of aneurysms in the supraclinoid internal carotid artery (ICA) are amenable to flow-diverter treatment $[1,6,12]$. However, an important concern is the patency of side branches covered by the device $[27,28,30]$. Although in vitro studies and experimental models have demonstrated long-term patency rates of arterial side vessels covered with a flow-diverter $[18,19]$, the rate and clinical consequence of ICA side branch occlusion after coverage with the stent remains not completely defined $[32,35,38]$. We performed a systematic review and meta-analysis of all the published studies examining the patency of the ophthalmic artery (OphtA), the posterior communicating artery (PcomA), and the anterior choroidal artery (AchorA) after coverage with flow-diverter devices. The purpose of our study was to determine the rate of OphtA, PcomA, and AchorA occlusion and the relative clinical sequelae. 


\section{Materials and methods}

\section{Literature search}

A comprehensive literature search of PubMed, Ovid MEDLINE, and Ovid EMBASE was conducted for studies published from 2008 to May 2017. PRISMA guidelines (Preferred Reporting Items for Systematic Reviews and Meta-analyses) were followed [23]. The key words "flowdiverter", "flow diversion", "side branches", "intracranial aneurysms", "pipeline”, were used in both "AND" and "OR" combinations. The inclusion criteria were the following: 1) studies reporting clinical and radiological outcomes of patients treated with flow-diverter in which the device was placed across the ostium of the OphtA, PcomA, or AchorA. Exclusion criteria were the following: 1) studies with <4 covered vessels; 2) case reports; 3) review articles; 4) studies published in languages other than English; 5) in vitro studies, animal studies, mathematical models. In cases of overlapping patient populations, only the series with the largest number of patients or most detailed data were included. Two reviewers independently selected the included studies, and a third author solved discrepancies.

\section{Data Collection}

From each study, we extracted the following information: 1) number of OphtAs, PcomAs, and AchorAs covered with flow-diverters; 2) rate of arterial occlusion, diminished flow and related symptoms; 3) factors related to arterial occlusion. In addition, we collected: 1) demographic data of patients; 2) aneurysm characteristics; 3) type and number of stents; 4) treatment-related outcomes. Factors associated to ICA branch occlusion were divided in three categories: demographic, technical, and anatomical factors.

\section{Outcomes}

The primary objectives were to determine: 1) the incidence of supraclinoid ICA branch occlusion, and related symptoms; 2) the factors related to the risk of arterial occlusion.

\section{Quality Scoring}


The Newcastle-Ottawa Scale [39] was used to assess the quality of the included studies (Supplemental Table 2). This was done by assessing the patient selection criteria, comparability of the study groups, as well as the outcome and exposure assessment. Criteria for "High-quality" were: 1) presence of a predefined study protocol; 2) defined inclusion and exclusion criteria; 3) clearly defined imaging protocol; 4) adequate assessment of arterial flow changes; and 5) adequate length of follow-up. A star rating of 0 to 9 was allocated to each study based on these parameters. The quality assessment was performed by 2 authors independently. When discrepancies arose, papers were re-examined by the third author. Studies receiving 6 or more stars are considered "highquality".

\section{Statistical analysis}

We estimated from each cohort the cumulative prevalence and $95 \%$ confidence interval for each outcome. Rates of each outcome were pooled in meta-analysis across studies using the randomeffects model[11]. We chose this model a priori because it incorporates both within-study variance and between-studies variance. This is recommended when data are heterogeneous. The heterogeneity of treatment effect across studies was evaluated using the I-squared $\left(\mathrm{I}^{2}\right)$ statistic, in which an $\mathrm{I}^{2}$ value greater than $50 \%$ suggests substantial heterogeneity[16]. Chi-square analysis was used to compare outcomes between groups when appropriate. Statistical analysis was performed using the software program OpenMeta[Analyst] (http://www.cebm. brown.edu/openmeta/).

\section{Results}

\section{Literature Review}

The search strategy is summarized in Supplemental Table 1, and the included studies are reported in Supplemental Table 2. The search flow diagram is shown in Supplemental Figure 1. The assessment of arterial occlusion and slow flow, and the relative radiological criteria, are summarized in Supplemental Table 3 .

A total of 21 studies and 1152 supraclinoid ICA branches covered with a flow-diverter were analyzed. The included articles were divided into three groups: 14 studies for the OphtA, 9 for the 
PcomA, and 8 for the AchorA. Six articles reported information about all of the 3 arteries, and the data were analyzed separately in each of the 3 groups.

\section{Quality of Studies}

Regarding the OphtA groups, 10 articles were considered "high-quality", whereas 4 studies were "low-quality". Among the PcomA group, 5 out of the 9 studies were rated "high quality". In the AchorA group's studies, half of the reported studies were considered "high quality".

\section{Patient Population and Aneurysm Characteristics}

The mean age of patients was 54 years (range 17-75), and the male/female ratio was 0.17 (Supplemental Table 4). Overall, 93.5\% (95\% CI=91-95.3\%) of ICA aneurysms treated with the flow diversion technique were unruptured, whereas $6.5 \%(95 \% \mathrm{CI}=4.6-6.9 \%)$ where previously ruptured and were treated with coils or clipping in the acute phase. The proportion of saccular and fusiform aneurysms was $97.7 \%$ (95\% CI=96.3-98.6\%), and 2.3\% (95\% CI=1.3-3.7\%), respectively. The mean size of aneurysms was $8.5 \mathrm{~mm}$ (range 3-38).

\section{Treatment Characteristics and Radiological Follow-up}

The most common device was PED $(95.8 \%, 95 \% \mathrm{CI}=96.3-98.6 \%)$, and most of the aneurysms were treated with one device (number of flow-diverters/aneurysm=1.2). Flow diversion was used as first treatment modality in $92.5 \%$ of cases (95\% CI= 89.4-95\%) (Supplemental Table 4).

Mean clinical and radiological follow-up was 12 months (range 6-29). In about 90\% of the reported patients, digital subtraction angiography (DSA) was performed during the early and long-term radiological follow-up. All cases of arterial flow changes were detected by DSA. In approximately $10 \%$ of cases, MRA or CTA were performed during the long-term radiological follow-up.

\section{Outcome of the Supraclinoid ICA Side Branches Covered with Flow-diverting Stents}

During a mean radiological follow-up of 12.3 months (median 12, range 6-29), the overall rate of supraclinoid ICA branches occlusion was $7.2 \%(95 \% \mathrm{CI}=4.9-9.6 \%)$ (incidence $=7 \%$ per patientyear follow-up) (Figure 1). 
Overall, 757 covered OphtAs were observed during a mean follow-up of 11.9 months (median 10.75, range 6-29) (Table 1). The rate of OphtA occlusion was 5.9\% (95\% CI=3.1-8.6\%) (incidence $=6 \%$ per patient-year), whereas $1.6 \%(95 \% \mathrm{CI}=0.5-2.8 \%)$ (incidence $=1.6 \%$ per patient-year $)$, of cases showed diminished flow (Supplemental Figure 2 A, B). The incidence of immediate postoperative occlusion or diminished flow after flow diversion was $1.2 \%$ (95\% CI=0.2-2.6\%) (Supplemental Figure 3A). No cases of symptomatic diminished flow were reported. On the contrary, $0.8 \%(95 \% \mathrm{CI}=0.1-1.4 \%)$ (incidence $=0.8 \%$ per patient-year), of treated patients were symptomatic after OphtA occlusion (monocular blindness or visual field deficit) (Supplemental Figure 4A).

Of the 196 PcomAs covered with stents, $20.7 \%$ 95\% CI=8.9-32.4\%) were occluded during a mean follow-up of 12.7 months (median 12, range 6-22.5) (incidence $=19.5 \%$ per patient-year), whereas $6.3 \%(95 \% \mathrm{CI}=1.8-10.9 \%)$ showed diminished flow (incidence $=5.9 \%$ per patient-year), (Supplemental Figure 5 A,B). Immediate post-operative flow changes were present in $4.4 \%$ of cases (95\% CI=1.6-10.5\%) (Supplemental Figure 3B). No patients reported symptoms related to flow changes of the PcomA.

Overall, 199 AchorAs covered by the device were available during a mean follow-up of 12.5 months (median 12, range 6-22.3). The incidence of occlusion was $1 \%(95 \% \mathrm{CI}=0.3-2.4 \%)$ (incidence $=0.96 \%$ per patient-year) (Supplemental Figure 6A). Similarly, arterial narrowing was reported in the same percentage of treated patients (Supplemental Figure 6B). No cases of immediate arterial flow changes were reported. The incidence of symptoms related to AchorA occlusion was $1 \%(95 \% \mathrm{CI}=0.4-2.3 \%)$ (transient hemiparesis and hemianopsia) (incidence $=0.96 \%$ per patient-year) (Supplemental Figure 4B).

\section{Factors Related to Arterial Flow Changes}

The mean age of patients with arterial flow changes was 52.4 years, whereas the mean age of patients with normal flow was 55.5 years $(\mathrm{p}=0.3)$ (Supplemental Table 5). The M/F ratio among patients with arterial occlusion or diminished flow was 0.1 . However, the prevalence of female 
patients in the group with arterial flow changes compared to the group with normal flow was not statistically significant ( $90 \%$ vs $80 \%, \mathrm{p}=0.43)$. Similarly, the prevalence of flow changes after coverage with single or multiple flow-diverters was comparable $(\mathrm{p}=0.8)$. There was a trend toward higher odds of arterial patency among arteries arising from the aneurysm (neck or dome) $(\mathrm{OR}=2.94$, $\mathrm{p}=0.06)$. Overall, 94.5\% (95\% CI $=82.2-99.4 \%)$ of patients with arterial occlusion presented adequate collateral circulation.

\section{Study Heterogeneity}

Significant heterogeneity was noted in the analysis of the overall rate of arterial occlusion. Among the OphtA group, significant heterogeneity was noted in the analysis of the OphtA occlusion during follow-up. Small heterogeneity was reported in the analysis of diminished flow of covered PcomA. Finally, significant heterogeneity was reported for the rates of PcomA occlusion during follow-up and immediate occlusion or slow flow during treatment.

\section{Discussion}

Flow diversion devices are widely used in the treatment of ICA aneurysms, allowing a high rate of angiographic success with a relatively low incidence of complications $[1,17,20]$. However, there are important concerns regarding possible occlusion of side branches, when the device is placed across the origin of the major supraclinoid ICA vessels $[27,28]$. One mechanism involved in the arterial side branch occlusion is the "flow competition" of the collateral supply pathways of the cerebral vasculature. Due to the high density of the mesh, the pressure gradient into the artery is decreased after stent coverage: consequently, the blood flow through the collateral arterial networks becomes increased. This results in a further decrease of the pressure gradient across the jailed artery, with a possible risk of occlusion [34]. The effect of flow diversion also depends on the local stent porosity that is influenced by the stent sizing. Berg et al. [2], in an animal model study, demonstrated that undersized stents are associated with a shorter deployment, more condensed pores, and higher mesh density, resulting in increased risks of side branch occlusion. In addition, in case of tortuous parent arteries, such as carotid siphon, the local stent deformation can influence the 
density of the pores, resulting in tighter mesh in the inner curves, with higher flow attenuation [33]. Our meta-analysis of nearly 1200 supraclinoid ICA vessels covered with flow-diverter stents demonstrated that the overall incidence rate of OphtA, PcomA, and AchorA occlusion was $7 \%$ per patient-year follow-up. However, the meta-analysis showed important differences among occlusion rates, diminished flow, and related clinical events among each specific artery.

\section{Ophthalmic Artery}

Of the 757 OphtA covered, roughly $6 \%$ were occluded (arterial occlusion rate of $6 \%$ per patientyear), with a low rate of clinically relevant related symptoms $(0.8 \%$ among treated patients). The most important mechanism related to the branch preservation is the pressure gradient between the parent artery and its branches. This allows an aspiration effect that preserve the flow after coverage with the stent [15]. However, in case of significant collateral circulation, the pressure gradient across the device is usually not enough and lead to branch occlusion [29]. The OphtA presents a consistent, distal collateral circulation from the external carotid artery and this supports the low rate of clinically overt visual symptoms in cases of branch occlusion [26, 41]. However, the correlation between OphtA occlusion and visual outcome is difficult, and the rate of symptoms related to flowdiverter placement across the ostium could be underestimated. Vedantam et al. [38], in a series of 49 OphtAs, reported 4\% of asymptomatic OphtA occlusion. However, 6 patients experienced new visual symptoms at follow-up related to thromboembolic events after OphtA coverage. Similarly, Rouchaud et al. [33], in a recent series of 28 patients, after a complete and extensive neuroophthalmological examination, reported $21.4 \%$ and $17.9 \%$ of transient and permanent complications after coverage of the OphtA with flow-diverting stents, respectively [33]. In addition, the origin of the artery from the aneurysm dome appear associated with a trend toward visual ischemic symptoms [15, 33]. Accordingly, although clinically well tolerated, the OphtA flow change may not be the only predictor of visual outcome after coverage with a flow-diverter stent.

\section{Posterior Communicating Artery}


Overall, nearly $20 \%$ and $6 \%$ of covered PcomA will undergo occlusion or will show diminished flow, respectively. In no cases were PcomA occlusion or slow flow associated with clinical symptoms. The aforementioned theory of gradient pressure may explain the high rate of occlusion of PcomA. In the most common pattern of posterior circulation, when the P1 artery is well represented, the direct connection to PcomA and the anastomotic circulation may explain the trend toward thrombosis of the PcomA [10]. Accordingly, the presence of a fetal variant, because PcomA represents the major supply to the posterior cerebral artery, creates a pressure gradient across the artery that preserves the flow and the patency of the PcomA. Accordingly, all of the studies included in our meta-analysis reported $100 \%$ of patency of the fetal variant after placement of flowdiverter stents $[9,10,21,30]$. Interestingly, PcomA showed higher rates of immediate occlusion or diminished flow after treatment, compared to the other locations. Similarly, Brinjikji et al.[5] reported that initial post-angiographic flow reduction was significantly associated with occlusion of the PcomA in the long-term follow-up. In conclusion, the incidence of symptoms after coverage of PcomA with flow-diverter stents is rare, even with the high rate of related occlusion and slow flow.

\section{Anterior Choroidal Artery}

While the anastomotic support of the OphtA and PcomA is well defined, the collateral supply of the AchorA remains not fully predictable, and coverage of the arterial ostium is strategically limited, giving the neurological eloquence of this vascular territory [22, 31]. Meta-analysis of the included studies showed a $1 \%$ incidence of AchorA occlusion with an arterial occlusion rate of $0.96 \%$ per patient-year. Most important, occlusion was clinically silent in most of cases, with approximately $1 \%$ of transient related symptoms. The pattern of collateral anastomosis with posterior choroidal branches, interpeduncular plexus, and PcomA could influence the rate of symptomatic occlusion, as well as the anatomical variants of AchorA. Takahashi et al. [37] described 7 cases of ICA obstruction, in which vertebral angiography demonstrated a retrograde filling of AchorA. In a series of 20 covered AchorAs, 14 of which were long-course variants, Neki et al.[25] reported no flow changes or symptoms after stent deployment, both in patients with long-course and short-course 
arteries. In a recent large series of 91 AchorAs covered with flow-diverter devices, Bhogal et al. [3] reported no arterial occlusion during 2 years of follow-up. The smaller diameter of the AchorA in comparison with the parent vessel, allows rapid blood flow through the stent into the artery, with a decreased tendency of occlusion $[18,25]$. Accordingly, the rarity of the angiographic occlusion and the low rate of neurological sequelae, demonstrated that placement of flow diversion devices across the ostium of AchorA, when it is mandatory during aneurysm treatment, is feasible and safe.

\section{Factors affecting the risk of ICA branches occlusion after flow diversion}

Understanding factors associated with ICA branch occlusion is important during flow diversion treatment of intracranial aneurysms. However, factors related to arterial occlusion are poorly investigated in the literature, and the available data is often contradictory. Our meta-analysis did not reveal any significant association between demographic factors and arterial flow changes. The number of devices is strategically limited during the treatment due to the higher mesh density across the artery. Chalouhi et al. [8] reported a higher rate of OphtA occlusion when covered by more than one device (21\% vs $8 \%$ ). Similarly, Puffer et al. [29] reported that the mean number of PEDs in the patients with occluded OphtA or change in flow was 2.4 vs 1.9. However, in other studies, the number of devices used during treatment was not a significant predictor of sluggish flow [9, 13]. We found that the incidence of arterial occlusion or slow flow was comparable among patients treated with one or multiple devices $(\mathrm{p}=0.8)$. Contrariwise, there was a trend toward higher odds of arterial patency among arteries arising from the aneurysm (neck or dome) $(\mathrm{OR}=2.94, \mathrm{p}=0.06)$. However, the persistent runoff into branches originating from the aneurysms is reported as a factor associated with lower rate of aneurysm occlusion, probably related to an incomplete neointimal response $[9,29,31]$. Antiplatelet therapy certainly plays an important role for the safety of the flow diversion treatment. However, there is scant data showing any relation between antiplatelet therapy and the risk of arterial occlusion after flow diversion. In a recent study, Durst et al [13] reported a higher P2Y12 Reactive Units (PRU) and Aspirin Reactive Units (ARU) in the subgroup with sluggish flow, than in the subgroup of normal flow, but the results were not significant. Finally, 
occlusion of covered branches is also the result of the presence of robust collaterals. We found that $94 \%$ of patients with arterial occlusion showed adequate collateral, supporting the observation that only few patients developed clinical consequences [7, 9, 13, 29, 31, 36, 41].

\section{Limitations of the Study}

Our study has several limitations. A language bias should be underlined because we exclusively selected studies published in English. First, $\mathrm{I}^{2}$ were above $50 \%$ for many of the estimates, suggesting substantial heterogeneity among the analysed outcomes. The articles reported are often small, retrospective, and single-institution series. Among studies rated "poor quality", the angiographic outcome of covered arteries could be not appropriately investigated. Accordingly, the rate of occlusion and the related symptoms could be underestimated. Although in most of the reported cases, flow-diverting stent was the first treatment, we were unable to comment about the influence of the previous treatments. Platelet responsiveness, an important factor in determining arterial patency following treatment, was not systematically assessed, due to the scant data available.

\section{Conclusions}

Our meta-analysis conclusively demonstrated that flow changes among covered ICA branches are non-worrisome after flow diversion treatment. OphtA and AchorA showed approximately $1 \%$ of symptomatic occlusion. Flow changes of the PcomA are common after flow diversion, and are clinically silent. Adequate collateral circulation is frequently associated with asymptomatic arterial occlusion, whereas demographic factors and multiple stents appear not to be associated with a higher risk of arterial impairment. 
Acknowledgments: We thank Prof. Beth De Felici for the English revision.

Disclosure of interest: The authors declare that they have no competing interest.

\section{References}

[1] Becske T, Kallmes DF, Saatci I, et al. Pipeline for uncoilable or failed aneurysms: results from a multicenter clinical trial. Radiology 2013; 267:858-868

[2] Berg P, losif C, Ponsonnard S, et al. Endothelialization of over- and undersized flow-diverter stents at covered vessel side branches: An in vivo and in silico study. J Biomech 2016; 49:4-12

[3] Bhogal P, Ganslandt O, Bazner H, et al. The Fate of Side Branches Covered by Flow Diverters results from 140 patients. World Neurosurg 2017; 103:789-798

[4] Brinjikji W, Kallmes DF, Cloft HJ, et al. Patency of the anterior choroidal artery after flow-diversion treatment of internal carotid artery aneurysms. AJNR Am J Neuroradiol 2015; 36:537-541

[5] Brinjikji W, Lanzino G, Cloft HJ, et al. Patency of the posterior communicating artery after flow diversion treatment of internal carotid artery aneurysms. Clin Neurol Neurosurg 2014; 120:84-88

[6] Brinjikji W, Murad MH, Lanzino G, et al. Endovascular treatment of intracranial aneurysms with flow diverters: a meta-analysis. Stroke 2013; 44:442-447

[7] Burrows AM, Brinjikji W, Puffer RC, et al. Flow Diversion for Ophthalmic Artery Aneurysms. AJNR Am J Neuroradiol 2016; (http://dx.doi.org/10.3174/ajnr.A4835).

[8] Chalouhi N, Daou B, Kung D, et al. Fate of the Ophthalmic Artery After Treatment With the Pipeline Embolization Device. Neurosurgery 2015; 77:581-584; discussion 584

[9] Daou B, Valle-Giler EP, Chalouhi N, et al. Patency of the posterior communicating artery following treatment with the Pipeline Embolization Device. J Neurosurg 2017; 126:564-569

[10] de Carvalho FM, Caroff J, Pereira Dos Santos Neto E, et al. Flow changes in the posterior communicating artery related to flow-diverter stents in carotid siphon aneurysms. J Neurointerv Surg 2016; 9(7):674-678.

[11] DerSimonian R, Laird N (1986) Meta-analysis in clinical trials. Control Clin Trials 7:177-188

[12] Deutschmann HA, Wehrschuetz M, Augustin M, et al. Long-term follow-up after treatment of intracranial aneurysms with the Pipeline embolization device: results from a single center. AJNR Am J Neuroradiol 2012; 33:481-486

[13] Durst CR, Starke RM, Clopton D, et al. Endovascular treatment of ophthalmic artery aneurysms: ophthalmic artery patency following flow diversion versus coil embolization. J Neurointerv Surg 2016; 8:919-922

[14] Gascou G, Lobotesis K, Brunel H, et al. Extra-aneurysmal flow modification following pipeline embolization device implantation: focus on regional branches, perforators, and the parent vessel. AJNR Am J Neuroradiol 2015; 36:725-731

[15] Griessenauer CJ, Ogilvy CS, Foreman PM, et al. Pipeline Embolization Device for small paraophthalmic artery aneurysms with an emphasis on the anatomical relationship of ophthalmic artery origin and aneurysm. J Neurosurg 2016; 125:1352-1359

[16] Higgins JP, Thompson SG, Deeks JJ, et al. Measuring inconsistency in meta-analyses. BMJ 2003; 327:557-560

[17] Kallmes DF, Brinjikji W, Boccardi E, et al. Aneurysm Study of Pipeline in an Observational Registry (ASPIRe). Interv Neurol 2016; 5:89-99

[18] Kallmes DF, Ding YH, Dai D, et al. A new endoluminal, flow-disrupting device for treatment of saccular aneurysms. Stroke 2007; 38:2346-2352 
[19] Kallmes DF, Ding YH, Dai D, et al. A second-generation, endoluminal, flow-disrupting device for treatment of saccular aneurysms. AJNR Am J Neuroradiol 2009; 30:1153-1158

[20] Kallmes DF, Hanel R, Lopes D, et al. International retrospective study of the pipeline embolization device: a multicenter aneurysm treatment study. AJNR Am J Neuroradiol 2015; 36:108-115

[21] Kan P, Duckworth E, Puri A, et al. Treatment failure of fetal posterior communicating artery aneurysms with the pipeline embolization device. J Neurointerv Surg 2016; 8:945-948

[22] Lee M, Saver JL, Hao Q, et al. Anterior choroidal artery ischaemic patterns predict outcome of carotid occlusion. J Neurol Neurosurg Psychiatry 2012; 83:586-590

[23] Moher D, Liberati A, Tetzlaff J, et al. Preferred reporting items for systematic reviews and metaanalyses: the PRISMA statement. Int J Surg 2010; 8:336-341

[24] Moon K, Albuquerque FC, Ducruet AF, et al. Treatment of ophthalmic segment carotid aneurysms using the pipeline embolization device: clinical and angiographic follow-up. Neurol Res 2014; 36:344-350

[25] Neki H, Caroff J, Jittapiromsak P, et al. Patency of the anterior choroidal artery covered with a flowdiverter stent. J Neurosurg 2015; 123:1540-1545

[26] Perrini P, Cardia A, Fraser K, et al. A microsurgical study of the anatomy and course of the ophthalmic artery and its possibly dangerous anastomoses. J Neurosurg 2007; 106:142-150

[27] Pierot L. Flow diverter stents in the treatment of intracranial aneurysms: Where are we? J Neuroradiol 2011; 38:40-46

[28] Pierot L, Biondi A. Endovascular techniques for the management of wide-neck intracranial bifurcation aneurysms: A critical review of the literature. J Neuroradiol 2016; 43:167-175

[29] Puffer RC, Kallmes DF, Cloft HJ, et al. Patency of the ophthalmic artery after flow diversion treatment of paraclinoid aneurysms. J Neurosurg 2012; 116:892-896

[30] Rangel-Castilla L, Munich SA, Jaleel N, et al. Patency of anterior circulation branch vessels after Pipeline embolization: longer-term results from 82 aneurysm cases. J Neurosurg 2016; 1-6

[31] Raz E, Shapiro M, Becske T, et al. Anterior choroidal artery patency and clinical follow-up after coverage with the pipeline embolization device. AJNR Am J Neuroradiol 2015; 36:937-942

[32] Roszelle BN, Gonzalez LF, Babiker MH, et al. Flow diverter effect on cerebral aneurysm hemodynamics: an in vitro comparison of telescoping stents and the Pipeline. Neuroradiology 2013; 55:751-758

[33] Rouchaud A, Leclerc $O$, Benayoun $Y$, et al. Visual outcomes with flow-diverter stents covering the ophthalmic artery for treatment of internal carotid artery aneurysms. AJNR Am J Neuroradiol 2015; 36:330336

[34] Saleme S, losif C, Ponomarjova S, et al. Flow-diverting stents for intracranial bifurcation aneurysm treatment. Neurosurgery 2014; 75:623-631; quiz 631

[35] Shobayashi Y, Tateshima S, Kakizaki R, et al. Intra-aneurysmal hemodynamic alterations by a selfexpandable intracranial stent and flow diversion stent: high intra-aneurysmal pressure remains regardless of flow velocity reduction. J Neurointerv Surg 2013; 5 Suppl 3:iii38-42

[36] Szikora I, Berentei Z, Kulcsar Z, et al. Treatment of intracranial aneurysms by functional reconstruction of the parent artery: the Budapest experience with the pipeline embolization device. AJNR Am J Neuroradiol 2010; 31:1139-1147

[37] Takahashi S, Suga T, Kawata $Y$, et al. Anterior choroidal artery: angiographic analysis of variations and anomalies. AJNR Am J Neuroradiol 1990; 11:719-729

[38] Vedantam A, Rao VY, Shaltoni HM, et al. Incidence and clinical implications of carotid branch occlusion following treatment of internal carotid artery aneurysms with the pipeline embolization device. Neurosurgery 2015; 76:173-178; discussion 178

[39] Wells G SB, O'Connell D. The Newcastle-Ottawa Scale (NOS) for assessing the quality of nonradomized studies in meta-analyses. Ottawa, ON: Ottawal Hospital Research Institute 2011. Ottawa Hosp Res Inst 1-4. doi: https://doi.org/10.2307/632432 Accessed May 2, 2017

[40] Yu SC, Kwok CK, Cheng PW, et al. Intracranial aneurysms: midterm outcome of pipeline embolization device--a prospective study in 143 patients with 178 aneurysms. Radiology 2012; 265:893-901

[41] Zanaty M, Chalouhi N, Barros $\mathrm{G}$, et al. Flow-diversion for ophthalmic segment aneurysms.

Neurosurgery 2015; 76:286-289; discussion 289-290 


\section{Figure Legend}

Figure 1. Forest plot demonstrating the overall rate of ICA branches occlusion (OphtA, PcomA, AchorA) following flow diversion treatment.

Supplemental Figure 1. PRISMA diagram detailing the specifics of the systematic literature review.

Supplemental Figure 2 (A, B). Forest plot demonstrating the overall rate of OphtA occlusion (Fig A) and diminished flow (Fig B) after coverage flow-diverter stents.

Supplemental Figure 3 (A, B). Forest plot demonstrating the incidence of immediate OphtA (Fig A) and PcomA (Fig B) flow changes after flow diversion.

Supplemental Figure 4 (A, B). Forest plot demonstrating the incidence of symptoms related to occlusion of OphtA (Fig A) and AchorA (Fig B) after coverage with flow-diverter.

Supplemental Figure 5 (A, B). Forest plot demonstrating the overall rate of PcomA occlusion (Fig A) and diminished flow (Fig B) after coverage flow-diverter stents.

Supplemental Figure 6 (A, B). Forest plot demonstrating the overall rate of AchorA occlusion (A) and diminished flow (B) after coverage flow-diverter stents. 


\section{Studies}

Bhogal P (OphtA) 2017

Burrows AM 2016

Griessenauer CJ 2016

Rangel-Castilla L (OphtA) 2016

Durst CR 2016

Rouchard A 2015

Chalouhi N 2015

Zanaty M 2015

Gascou G 2015

Vedantan A 2015

Moon K 2014

Puffer CR 2012

Yu SCH (OphtA) 2012

Szikora I (OphtA) 2010

Bhogal P (Pcom) 2017

Daou B 2016

Rangel-Castilla L (PcomA) 2016

de Carvalho FM 2016

Kan P 2015

Vendatan A (PcomA) 2015

Brinjikji W (PcomA) 2014

Yu SCH (PcomA) 2012

Szikora I (PcomA) 2010

Bhogal P (AchorA) 2017

Rangel-Castilla L (AchorA) 2016

Neki H 2015

Brinjikji W (AchorA) 2015

Raz E 2015

Gascou G (AchorA) 2015

Vendatan A (AchorA) 2015

Szikora I (AchorA) 2010

Overall (I^ $2=75.84 \%, P<0.001)$
Estimate $(95 \%$ C.I.) Ev/Trt

$\begin{array}{llll}0.053 & (0.015,0.091) & 7 / 133 \\ 0.216 & (0.084,0.349) & 8 / 37 \\ 0.033 & (0.000,0.077) & 2 / 61 \\ 0.105 & (0.036,0.174) & 8 / 76 \\ 0.025 & (0.000,0.093) & 0 / 19 \\ 0.036 & (0.000,0.104) & 1 / 28 \\ 0.063 & (0.014,0.112) & 6 / 95 \\ 0.205 & (0.085,0.324) & 9 / 44 \\ 0.059 & (0.000,0.138) & 2 / 34 \\ 0.041 & (0.000,0.096) & 2 / 49 \\ 0.026 & (0.000,0.077) & 1 / 38 \\ 0.211 & (0.027,0.394) & 4 / 19 \\ 0.005 & (0.000,0.017) & 0 / 107 \\ 0.118 & (0.000,0.271) & 2 / 17 \\ 0.426 & (0.284,0.567) & 20 / 47 \\ 0.533 & (0.355,0.712) & 16 / 30 \\ 0.107 & (0.000,0.222) & 3 / 28 \\ 0.278 & (0.071,0.485) & 5 / 18 \\ 0.100 & (0.000,0.363) & 0 / 4 \\ 0.071 & (0.000,0.206) & 1 / 14 \\ 0.231 & (0.002,0.460) & 3 / 13 \\ 0.054 & (0.000,0.127) & 2 / 37 \\ 0.083 & (0.000,0.304) & 0 / 5 \\ 0.005 & (0.000,0.020) & 0 / 91 \\ 0.023(0.000,0.085) & 0 / 21 \\ 0.028 & (0.000,0.104) & 0 / 17 \\ 0.067 & (0.000,0.193) & 1 / 15 \\ 0.034 & (0.000,0.101) & 1 / 29 \\ 0.042 & (0.000,0.155) & 0 / 11 \\ 0.042 & (0.000,0.155) & 0 / 11 \\ 0.100 & (0.000,0.363) & 0 / 4\end{array}$

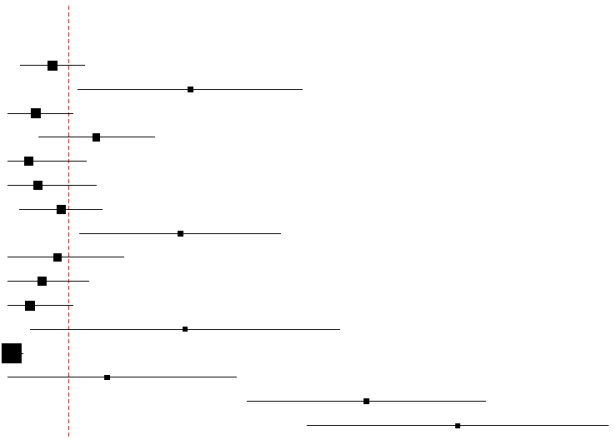

$0.072(0.049,0.096)$

$104 / 1152$

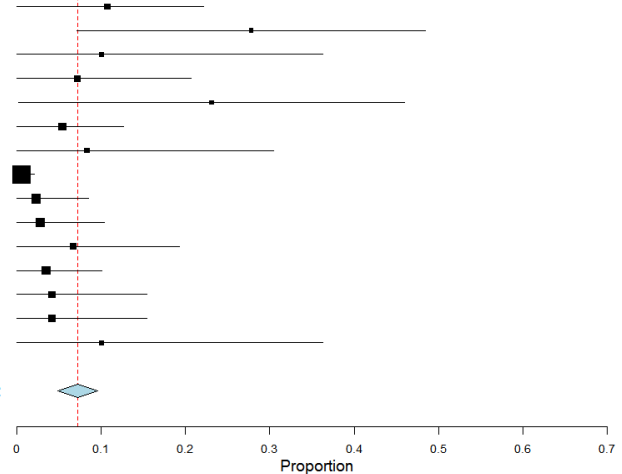


Table 1. Flow changes in ICA branches (Ophthalmic Artery, Posterior Communicating Artery, Anterior Choroidal Artery) covered with flow-diverter stents.

\begin{tabular}{|c|c|c|c|}
\hline \multirow{2}{*}{$\begin{array}{c}\text { Angiographic Outcomes } \\
\text { of Covered Arterial Side } \\
\text { Branches } \\
\text { (Meta-analysis) }\end{array}$} & \multicolumn{3}{|c|}{ ICA BRANCHES } \\
\hline & $\begin{array}{c}\text { OphtA } \\
\text { (14 Studies) }\end{array}$ & $\begin{array}{c}\text { PcomA } \\
\text { (9 Studies) }\end{array}$ & $\begin{array}{c}\text { AchorA } \\
\text { (8 Studies) }\end{array}$ \\
\hline $\begin{array}{l}\text { Diminished Flow } \\
\text { (during follow-up) }\end{array}$ & $\begin{array}{c}22 / 757=1.6 \% \\
C l 95 \%=0.5-2.8 \% \\
\left(I^{2}=37.63 \% ; p=0.076\right)\end{array}$ & $\begin{array}{c}17 / 196=6.3 \% \\
\mathrm{Cl} 95 \%=1.8-10.9 \% \\
\left(I^{2}=50.93 \% ; p=0.038\right)\end{array}$ & $\begin{array}{c}1 / 199=1 \% \\
C l 95 \%=0.3-2.4 \% \\
\left(I^{2}=0 \% ; p=0.924\right)\end{array}$ \\
\hline $\begin{array}{c}\text { Occlusion } \\
\text { (during follow-up) }\end{array}$ & $\begin{array}{c}\mathbf{5 2} / \mathbf{7 5 7}=\mathbf{5 . 9 \%} \\
\mathrm{Cl} 95 \%=3.1-8.6 \% \\
\left(1^{2}=69.32 \% ; p<0.001\right)\end{array}$ & $\begin{array}{c}50 / 196=20.7 \% \\
\mathrm{Cl} 95 \%=8.9-32.4 \% \\
\left(I^{2}=81.48 \% ; p<0.001\right)\end{array}$ & $\begin{array}{c}2 / 199=1 \% \\
C l 95 \%=0.3 .-2.4 \% \\
\left(I^{2}=0 \% ; p<0.878\right)\end{array}$ \\
\hline Mean Follow-up & $\begin{array}{l}11.9 \text { months } \\
\text { (range 6-29 months) }\end{array}$ & $\begin{array}{c}12.7 \text { months } \\
\text { (range 6-22.5 months) }\end{array}$ & $\begin{array}{c}12.5 \text { months } \\
\text { (range 6-22.3 months) }\end{array}$ \\
\hline $\begin{array}{l}\text { Immediate Occlusion or } \\
\text { Diminished Flow } \\
\text { (during treatment) }\end{array}$ & $\begin{array}{c}* 14 / 482=1.2 \% \\
C I 95 \%=0.2-2.6 \% \\
\left(I^{2}=46.07 \% ; p=0.062\right)\end{array}$ & $\begin{array}{c}* * 7 / 106=4.4 \% \\
C l 95 \%=1.6-10.5 \\
\left(I^{2}=63.66 \% ; p=0.041\right)\end{array}$ & No Changes \\
\hline $\begin{array}{l}\text { Symptoms Related to } \\
\text { Flow Changes }\end{array}$ & OphtA & PcomA & AchorA \\
\hline $\begin{array}{c}\text { Symptomatic Diminished } \\
\text { Flow }\end{array}$ & No symptoms & No symptoms & No symptoms \\
\hline & $\# 2 / 650=0.8 \%$ & & $\# \# 1 / 178=1 \%$ \\
\hline Symptomatic Occlusion & $\begin{array}{l}\mathrm{Cl} 95 \%=0.1-1.4 \% \\
\left(\mathrm{I}^{2}=0 \% ; p=0.998\right)\end{array}$ & No symptoms & $\begin{array}{l}\mathrm{Cl} 95 \%=0.4-2.3 \% \\
\left(I^{2}=0 \% ; p=0.882\right)\end{array}$ \\
\hline
\end{tabular}

* 9 studies available; $* * 4$ studies available

\# 13 studies available;

\#\# 7 studies available. 